\title{
Imposition Of Diversity: The Imposition Of Diversity-Training Through Top Down Management Communication
}

\author{
Stephanie Thibeaux, Student, Prairie View A\&M University \\ Gwen Tillotson, Student, Prairie View A\&M University \\ Terrance Falls, Student, Prairie View A \& M University \\ Reginald L. Bell, (E-mail: rlbell@pvamu.edu), Prairie View A \& M University
}

\begin{abstract}
Top managers should impose diversity-training programs requiring all managers to participate. A diversity program must focus on enhancing managerial communication competence, while taking into consideration the impact that various cultures, religions, family structures and attitudes will have on managerial communication processes. If executives are to attain goal achievement and motivate employees, they must be prepared to effectively impose diversity training on an inherently diverse workforce. The benefits of properly implementing and consistently supporting a diversitytraining program could outweigh managerial resistance.
\end{abstract}

\section{INTRODUCTION}

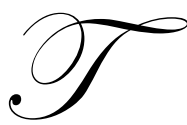

he American workforce is evolving every day and it is comprised of people from different nationalities, ethnic groups, languages, and religions. In other words, population trends have changed the demographic direction of our nation towards diversity. Therefore, a "one size fits all" notion of managing people has become archaic and obsolete jargon. If modern workforces are managed appropriately, American companies (not immune from demographic trends) might experience a boon of untapped potentiality. A report prepared by the Hudson Institute for the U. S. Department of Labor provided some insight into the impending demographic changes in the American workforce, more than 13 years ago.

That report indicated a significant increase in women and minority entrants into the workforce. Von Bergen (2002) mentions some organizations have begun undertaking diversity initiatives seriously in preparation for the changing U. S. population. The diversity dynamics associated with the changing workforce will have a direct impact on organizations' human resources functions, such as recruitment efforts, training and retention programs, and it will indubitably have an effect on industries and professions across the globe. At least one accounting organization embraced early the challenges associated with cultivating a diverse professional workforce.

In 1991, the AICPA (Accounting Institute of CPA's) implemented its diversity initiative. A subcommittee was formed and a partnership with the National Association of Black Accountants (NABA) was established to attract more minorities to the accounting profession. The organizational effort was expanded to not only include increased awareness to minority students and professionals but also provided mentorship opportunities, and it organized a committee to enhance the focus of its resources on minority retention and promotion. People from varied cultures are bringing their talents and abilities to organizations, once dominated by people of a seemingly common race, with seemingly shared cultural values and belief systems.

Munter (1993) writes "culture consists of shared values, attitudes and behavior in a given group of most of the people most of the time" (p.1). To effectuate positive change through managerial communications, diversitytraining programs will require necessary questions be answered. What impact do shared backgrounds have on management competence (bottom line) and managerial communication effectiveness (directive feedback and action)? 
It may be reasonable to surmise that managers might be better able to more effectively manage employees similar to their own races, cultures, and backgrounds; however, why is the notion of "similar-to-me-effect" impact only management competence tolerable in a globally diverse workplace environment?

Management skills correlate with intended employee outcomes; furthermore, there appears to be evidence that personnel groups sharing similar cultures are associated with the likelihood of consistent behavioral responses. In other words, managers are often better able to effectively reinforce positive employee patterns and discourage negative behaviors within a common group. This may be due to the stock-of-knowledge the respective manager might possess about the similar culture. Perhaps managers give more attention to the feelings of employees and offer forbearance to others they deem similar to themselves - a "similar-to-me-effect" kind of benefit; notwithstanding, more pressing questions must be answered. What happens to management communication competence when employees represent diverse cultural and ethnic groups imposed by a changing national demographic trend towards diversity? Can the answer be found in the current literature?

\section{Need For Diversity-Training}

The word diversity is not new to the American vernacular; it has been around for many years. However, the meaning of the word diversity continues to evolve as the United States changes its demographics. Merriam-Webster $3^{\text {rd }}$ edition defines diversity as "the condition of being different or having differences". Earlier research focused mainly on race and gender differences. Current research focuses on employee differences originating form ethnicity, culture, lifestyle, age, social status, educational background, and extending to physical or mental challenges. Corporate globalization turns diversity issues into management problems where wrong answers can have disastrous bottom-line results (Barbian, 2003). Diversity is becoming more denoted and expansive; it can have a deep impact on an organization in many ways, thus having a direct impact on effective managerial communications. Problems are created if diversity-training programs are not implemented appropriately.

\section{Logic Of A CEO Communication Process Model}

Multiple challenges, including communication barriers, can exit when managers are responsible for providing guidance, stimulating motivation, and setting production goals for a diverse group of employees. Language can masquerade as a meaningful dialogue while at the same time reducing the effectiveness of communication. There exists a plethora of variations in the English language including inappropriate jargon, slang, colloquial dialects and accentuation issues that vary among people. Preexisting communication barriers within countries, regions, organizations, groups and professions are manifest when common goals need to be achieved: goals are thwarted by defective competence and field of experience issues. For instance, some members of the accounting profession would instantly recognize the acronym NABA, to represent The National Association of Black Accountants. However, if a professional botanist saw "NABA" the interpretation would likely represent something completely different: the North American Butterfly Association. In any profession, the use or misuse of jargon or non-verbal gestures can be a common problem.

Munter (1993) asserts that managers should understand challenges associated with nonverbal barriers to effective communications, and the impact wrongful usage of gesticulations could have on the communication process. However, there are still managers unaware that unpleasant nonverbal communications can complicate communication processes. Executives and managers must be cautious in their use of nonverbal behaviors in order to avoid offensive gestures, resulting in contradictory or nonproductive behavior from their employees. Managers must work diligently to ensure employees are receiving and interpreting the intended messages associated with their managerial communication purposes.

Effective managerial communication within a culturally diverse organization is essential for goal accomplishment. Munter (1993) writes "Managerial communication can be described as communication in a management context to achieve a desired result." The types of managerial communications can include writing a memo, conducting applicant interviews, presiding over meetings and conducting presentations. Notwithstanding, a more useful definition for Managerial Communication is prescriptive: it is the downward, horizontal or upward 
exchange of information and transmission of meaning through informal or formal channels that enables managers to achieve goals. Shockley-Zalabak (1988) presents an elegant model of the communication process that plainly illustrates how "noise" could distort a message (25). Littlejohn (1989) writes, "The most thorough discussion" of the Transmissional Perspective can be found in C. David Mortensen (1972), Communication: the Study of Human Interaction. Littlejohn (1989) provides a brief summary of the "Transmissional Perspective":

Transmissional theories view communication as the transfer of information from a source to receiver. They use a linear model of movement from one location to another. This perspective stresses communication media, time, and sequential elements. Generally it is based on World View I and nonactional assumptions, (27).

A working model on how knowledge of CEO transference of information could be viewed from a Transmissional Perspective is presented in Figure 1 below. The transfer of information in this model as it originates from a source (CEO who encodes and sends the diversity-training message) and a receiver (any subordinate manager who receives and decodes the diversity-training message) is considered a linear movement.

Figure 1: The CEO Diversity Communication Process Model

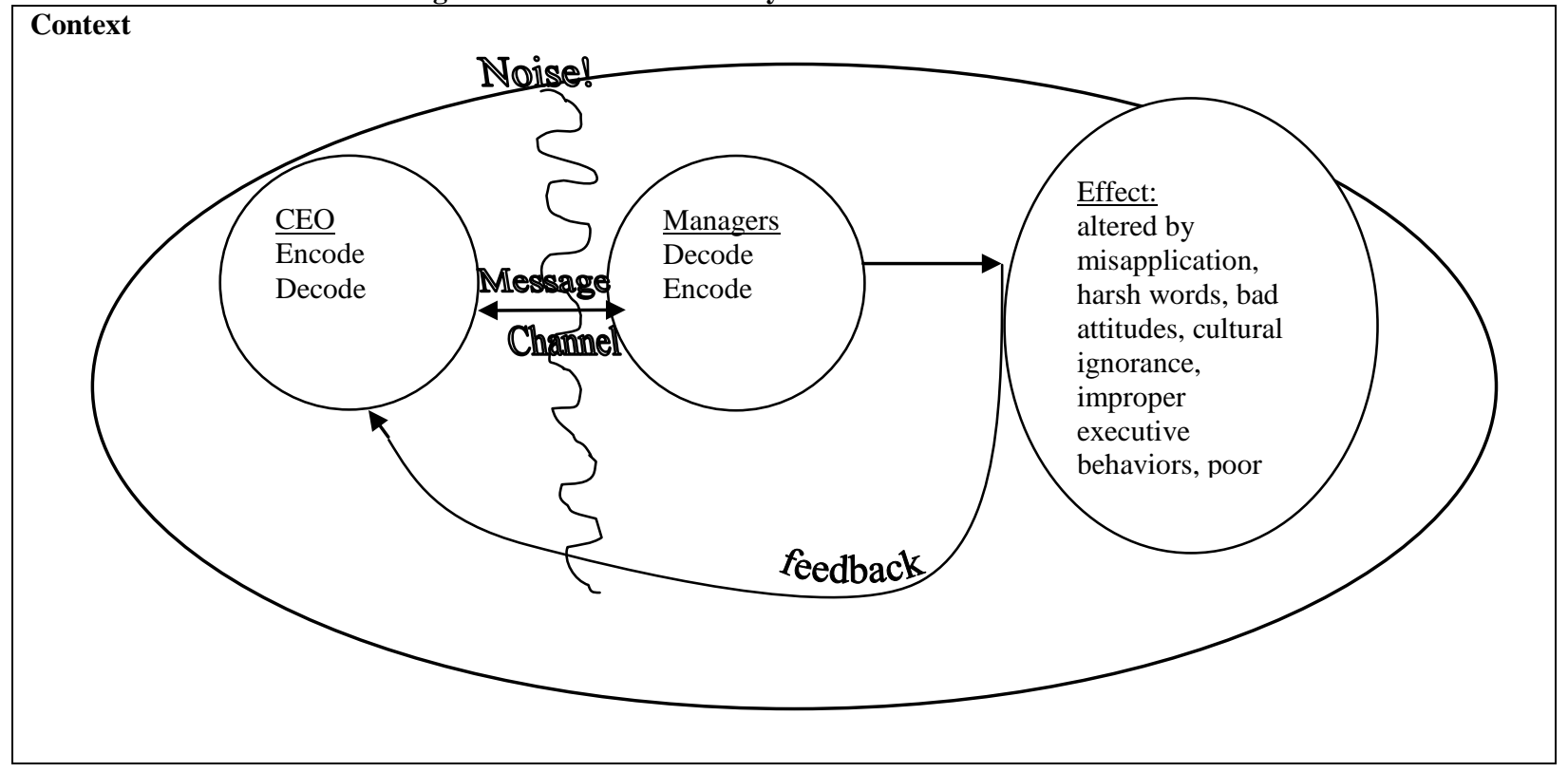

Noise can be defined in the model as any distorting or distracting CEO behavior not germane to the message of diversity training itself. In Figure 1 "noise" is represented by the squiggly line crashing down like lightning through the transfer of information, between the CEO (source) and receiver (any subordinate manager) that penetrates the message/channel; this illustrates noise as a disruptive distortion, verbal or nonverbal. A diversity message plagued with noise (managerial misapplication, harsh words, bad attitudes, cultural ignorance, improper executive (CEO) behaviors, poor implementation, etc) might be completely distorted, resulting in an altered effect or failed communication.

Behaviors prone to foster noise problems between CEO and receiver are lack of follow through, perceptions by subordinate managers of CEO insincerity, no oversight, failure to verify results, etc; noisy messages are often signals to others about the CEO's true intent, and manager's feedback to the CEO is normally that of non-compliance with the diversity-training messages. Communication is essential for organizational culture; however, since diversity training is the emphasis of the paper, imposing it as a top-down directive shall be the focus of the proposition. 
Katz and Kahn (1966) make mention of five types of downward communication from the superior level to the subordinate level. Wanguri (1996) warns an ever-increasing diversity in the workplace trend will continue. Managers cannot afford to use outdated communication techniques. If managers are to effectively motivate a diverse group of employees, top-level managers must incorporate diversity initiatives as a part of the overall human capital strategy, thereby making it an imposition. Without executive support, diversity initiatives are typically extremely ineffective.

\section{Diversity-Training As Imposition}

Gray (2005) suggests senior executives provide leadership to align an organization with its vision; therefore, a well planned diversity initiatives and its implementation must be aligned with the overall corporate vision; a sense of balance, shared respect and harmony are needed. Diversity initiatives need to be imposed by the CEO as a part of an overall diversity management plan. Diversity management includes administering social environments and systems, along with organizational climate, procedures, recognition and being open to and utilizing human differences (Von Bergen, 2002). One catalyst that might enhance management competence is a diversity-training program initiative from the top down.

Organizations can create a culture of open communication, enhance productivity and achieve organizational goals by using a comprehensive curriculum for a diversity-training program. The implementation of an effective diversity-training program involves more than just hiring a training specialist and allowing minority and majority groups to openly share their frustrations and concerns. This particular implementation procedure has historically been ineffective, and it can also result in the minority group feeling demoralized and the majority group feeling the effects of reverse discrimination. To achieve effective results of a diversity-training program, the CEO or top-level manager must adhere to a system of support and conduct needs assessments and be prepared to use a variety of methods and media to accomplish the strategic diversity goal.

\section{Problem Areas Identified In The Literature}

Communication is a process where meaning is exchanged between individuals or groups through some organized system of symbols, words, or signs (Phillips, 1985). World View I is a strong determinant of communication patterns (Swanson, 2002). Diversity may represent noise in the managerial communication process, if improper or the absolute lack of training negates reception of the message. Diversity may have a negative impact on managerial communication by transmission error (the meaning of the message misconstrued). Therefore, understanding the purpose of diversity training is an important factor for effective managerial communication. Diversity is more complex than the unspoken, but the underlying assumption is that it brings conflict, which can hinder work performance and lower productivity (Swanson, 2002). Diversity training can result in miscommunications throughout an organization if improperly imposed, implemented, and not supported by management from the top down. Managers today lead a diverse group of employees and must be prepared to effectively communicate with each member in order to achieve the desired result.

Their employees represent different religions, races, nationalities, and genders, physical, and psychological abilities. Managers face the challenges associated with these differences on regular basis, because they influence the managerial communication process. Managers today could become excellent communicators as a result of diversitytraining initiatives. Communicating with a variety of human differences is a challenge for many managers. The challenge must be met with realistic solutions to the changing national demographic trend towards diversity that has been an evolving reality with an impact on organizations' bottom-lines (Capowski, 1996).

Lewis, Goodman, and Fandt (1995) express their view on classical theories of organizational behavior. Theorist Chester Barnard (1938), who is considered a pioneer in the behavioral approach, makes a major contribution with his Functions of the Executive, and he placed significant emphasis on communication as the most important executive function. Brown (1973) writes about the communication transaction process. He believes a system should be developed to ensure the message and symbols between sender and receiver is translated properly and that "communication is organization in action." 
Communication is important in an organization due to its diversity (Smeltzer, Leonard, \& Hynes, 2002). The exchange of information and the transmission of meaning are the components of an organizational social system (Katz \& Kahn, 1966). Communication is a two-way process that has many obstacles able to influence the process (Phillips, 1985). Some obstacles include the medium itself, the message sent, and the attitude of both the source and receiver. Communication should be developed to ensure the message and symbols between sender and receiver. The aforementioned arguments are clearly a Transmissional Perspective.

Peter F. Drucker (1974) explains that communication does not exist unless the message can key into the recipient's own values, at least to some degree. Morand (1996) writes that a strategic approach to communication and the strategic model should be used, as it is important and describes the different layers that help explain the communication process and culture. Cross-cultural communication and cross-cultural training politeness, managerial communication, and diversity were determined to be an important part of effective cross-cultural communication. Arai, Wanca-Thibault, and Schockley-Zalabak (2001) focus on human communication and the lack of important information on different aspects of communication research. They believe new studies would show the importance of incorporating communication theories into diversity-training efforts.

Koonce (2001) contends that the need for diversity programs is growing. There are important steps to successfully implementing a diversity program. The steps include obtaining top-level leadership support, conducting a needs assessment and embedding a large framework, researching best practices, using diversity as a business advantage, designing informational and transformational programs, using multiple methods and media, and recognizing individual roles. Pollar (1998) says there is a framework for setting up successful diversity initiatives. This framework includes five steps that should be taken to effectively deal with diversity which are (1) creating a task force, (2) designing a cultural audit, (3) strategy development, (4) training, and (5) measuring results.

Results of a survey by Rynes and Rosen (1994) show a short-term positive impact on attitudes to diversity training. Top management showed support by associating the training with strategic priorities. Another study by Gilbert, Stead, and Ivancevich (1999) uncovers positive results and effectiveness of diversity management in organizations that implemented effective strategies.

Research by Reichenberg (2001) on diversity management shows a positive impact on performance when senior management teams are diverse. The contingency perspective view proposes that managerial style is situationspecific. Daft (1993) discusses future issues that managers will face like diversity, globalization, and quality. Diversity surveys by Grossman (2000) were conducted on race in the workplace. The majority, white males, will soon be the minority. Women are the majority of new entrants into the workforce. The importance of diversity management has created a need for diversity training (Von Bergen, 2002).

Wanguri (1996) explores relationships between workforce diversity and the resulting perceptions of inequity in the workplace and finds communication openness to be a solution to organizational problems. Post September 11, organizations have had to put more emphasis on diversity enrichment programs says Gardenswartz and Rowe (2001). Some diversity programs are more effective than others and the key to the success of a program lies in its implementation.

Executives play a large role in promoting effective managerial communication and diversity initiatives. The role of executives and their influence on employees' behavior were examined. Klein (2004) says executives set the tone for the communication culture of an organization. He comments that neither the stated values in a mission statement, or the content of newsletters influences employees of an organizations as much as how the executives treat others, and what they do and say.

Gray and Robertson (2005) examine the importance of diversity training imposed by the CEO or senior executives. Although most employees agree that the executive staff is responsible for communication the company's vision, objective and goals, many executives are not very visible. Improving communications between executives and employees is the most effective way to improve employee satisfaction; this is consistent with Barnard (1938). Turner 
(1992) highlights the result of a Workforce 2000 report, which describes the proactive approach of the AICPA to attract, retain and promote minority students.

The literature located, reviewed, and evaluated was expressly helpful in determining a new methodology for the top executive. A discussion on what top managers should do in order to implement a successful top-down diversity-training program is presented in the next section. The literature review revealed several important articles used in synthesizing the position and developing a proposed new methodology.

\section{THE PROPOSED METHODOLOGY}

An examination of secondary sources were used in order to determine the effects diversity-training programs had on executives' managerial communication, diversity and managerial communication, and diversity-training programs. First, evidence was located on the role of executives on managerial communication towards diversity trends. Second, An evaluation of diversity as a social system and its impact on communications was made. Third, an examination of diversity management and the role that top-level executives have in diversity initiatives was made. Findings support the importance of top-level managers' in implementing a diversity-training program to increase managerial communication effectiveness in support of the demographic diversity trends in modern organizations.

\section{Findings}

The new view is consistent with findings: support from top-level executives should directly influence the imposition and implementation of an organization wide diversity-training program to improve managerial communication processes. The role of executives in managerial communication, diversity trends, diversity management, and the need for diversity-training programs as a solution to effective managerial communication can now be better explicated.

\section{Executives And Managerial Communication}

Executives influence the communicative tone within an organization in many ways. Executives set the standard regarding communication and the subordinate management staff and employees typically mimic that standard. Employees of an organization focus on what the leaders of that organization focus on (Koonce, 2001). The CEO and other top executives take the lead role in establishing the overall communication culture of the organization (Barnard, 1938).

The most important area of communication is an ongoing organization...the personality of the sender is part of the message (Brown, 1973). To further support this position, Klein (2004) states that the behavior of senior managers, their treatment of others, the examples they set and the decisions they make, all set a tone, imbues a real personality, and an attitude in an intangible institution. The roles of top-level managers are important in managerial communication.

Executives serve many different roles in communication. Chester Barnard considered there to be two functions of executive communication. The first function of an executive is to establish a communication system among employees. The second function is to assume responsibility for formulating the objective and purpose of an organization and motivate employees to obtain these objectives. Barnard viewed organizations as social systems, which need cooperation from employees and continuous communication for effectiveness. In addition, symbols used in communication in the leadership of an organization require a sustained system of interaction (Brown, 1973). A major social system that affects managerial communication contingencies is diversity.

Diversity is part of culture. Communication happens within culture. Culture affects how managers communicate and bind members of organizations together through shared values and social ideals. Climate and culture is the first layer of the strategic approach to communication (Smeltzer, Leonard, Hynes, 2002). Top-level managers need to be able to communicate with different cultures at all levels of the organization as diversity is expanding. 
Within the next decade, women and people of color will fill 75 percent of new jobs, and by 2010, white men expect to account for less than 40 percent of the total workforce (Arai, Wanca-Thibault, and Schockley-Zalabak, 2001). This expected change shows organizations are becoming more diverse, making diversity an important factor for managers. Next, diversity trends and managerial communication will be highlighted.

\section{Diversity And Managerial Communication}

Trends in diversity illustrate the importance and continuance of diversity education and training. Table 1 below shows expected diversity trends. A turn of the millennium estimation of only 15 percent of new entrants to the workforce will be white males (Grossman, 2000).

Table 1: Diversity Trends

\begin{tabular}{|c|c|c|c|}
\hline \multicolumn{4}{|c|}{ Entrants to the Workforce } \\
\hline \multicolumn{4}{|c|}{ Net New Entrants into the workforce between 1994 and 2005} \\
\hline \multicolumn{2}{|c|}{ Total Workforce } & \multicolumn{2}{|c|}{$100 \%$} \\
\hline \multicolumn{2}{|c|}{ All minorities, both sexes } & \multicolumn{2}{|c|}{$51 \%$} \\
\hline \multicolumn{2}{|c|}{ White, non-Hispanic, both sexes } & \multicolumn{2}{|c|}{$49 \%$} \\
\hline \multicolumn{2}{|c|}{ Women, all ethnic groups } & \multicolumn{2}{|c|}{$62 \%$} \\
\hline \multicolumn{4}{|c|}{ Source: Workforce 2020, Hudson Institute (With Permission) } \\
\hline \multicolumn{4}{|c|}{ U.S. Labor Force } \\
\hline & Percentage 1995 & Percentage 2005 & Percentage 2020 \\
\hline Whites, Non -Hispanic & $76 \%$ & $73 \%$ & $68 \%$ \\
\hline Women & $46 \%$ & $48 \%$ & $50 \%$ \\
\hline Hispanic & $9 \%$ & $11 \%$ & $14 \%$ \\
\hline African American & $11 \%$ & $11 \%$ & $11 \%$ \\
\hline Asian American & $4 \%$ & $5 \%$ & $6 \%$ \\
\hline
\end{tabular}

The management ranks will need to vary as needs to exhibit a similar level of diversity grows (Daft, Bettenhausen, and Tyler, 1993). Managing diversity in the workplace is a subject that has gained increased attention among managers within the last twenty years. With the increase trends in diversity, diversity management is important for an organization's success.

\section{Diversity Management}

The CEO and Top-level management play an important role in diversity management. Diversity management is characterized as the mindset of an organization, the climate of an organization, and the different perspectives people bring to an organization due to race, styles, and disabilities (Reichenberg, 2001). Effective approaches to diversity management are strategic and focused on attainable goals (Swanson, 2002). Executive support of diversity management initiatives to enhance communication is important for successful diversity-related results.

Top management support is essential for many reasons. For positive diversity results, CEO initiation and continuation of diversity initiatives leads to transformation of the human resource function, positive individual 
outcomes, and positive attitudes towards diversity (Gilbert, Stead, \& Ivancevich, 1999). For diversity initiatives to succeed, they need support and involvement of a company's CEO and top leadership team, who should clearly state the importance of diversity as a business value and goal (Koonce, 2001). Without commitment from top managers, diversity initiatives will not succeed. If this happens, communication will not improve and diversity barriers will still exist. There is a five-step framework to setup successful diversity initiatives (Pollar, 1998). That framework is presented in Table 2:

Table 2: Pollar's Five-Step Framework

\begin{tabular}{|ll|}
\hline 1. & Create A Diversity Task Force \\
\hline 2. & Design A Cultural Audit \\
\hline 3. & Develop An Overall Strategy \\
\hline 4. & Deliver Training \\
\hline 5. & Measure Its Effectiveness \\
\hline
\end{tabular}

Pollar's step four, training, is particularly interesting. A diversity-training program should be implemented as a way to effectively increase managerial communication. Diversity training increases diversity awareness, encourages understanding, and creates a more productive work environment. The need for diversity programs has increased over the years. Three-quarters of companies have or will begin diversity-training programs (Rynes, Rosen, 1994). Training programs designed to enhance managerial effectiveness at cross-cultural communication are geared at specific target cultures (Morand, 1996). A diversity-training program would lead to better knowledge on how to communicate more effectively with people from different groups within the organization.

\section{Diversity-Training}

Diversity-training programs have been implemented by many organizations across the country. In order to improve downward communication, there are key components, which lead to an effective diversity-training program. A ten-step plan (Gardenswartz, Rowe, 2001) to build a stronger diversity-training program can be followed, see Table 3 below:

Table 3: Ten Step Plan to Build a Strong Diversity-training Program

\begin{tabular}{|ll|}
\hline 1. & Define It \\
\hline 2. & Commit To It \\
\hline 3. & Assess It \\
\hline 4. & Justify It \\
\hline 5. & Develop It \\
\hline 6. & Design It \\
\hline 7. & Communicate It \\
\hline 8. & Measure It \\
\hline 9. & Embed It \\
\hline 10. & Expect Discomfort \\
\hline
\end{tabular}

In order to successfully implement a Diversity-training Program (Tactical Implementation) several steps should be taken. Organizations must follow eight well- defined steps to implement an effective diversity-training program (Koonce, 2001). Those eight steps are presented in Table 4 below: 
Table 4: Koonce's Eight Well-Defined Steps on Implementing Diversity-training

\begin{tabular}{|rl|}
\hline 1. & Obtain Top-Level Leadership Support \\
\hline 2. & Conduct A Needs Assessment \\
\hline 3. & Embed In A Larger Framework \\
\hline 4. & Search Best Practices \\
\hline 5. & Use Diversity As A Business Strategy \\
\hline 6. & Design Informational And Transformational Programs \\
\hline 7. & Use Various Methods And Media \\
\hline 8. & Recognize Your Role \\
\hline
\end{tabular}

Top-level managers must implement key strategies to support diversity initiatives to improve the effectiveness of a diversity-training program. In order for diversity initiatives to be successful, the program should be aligned with corporate strategies and help define and drive other HR organizational initiatives, such as employee recruitment, development, rewards and advancement (Koonce, 2001).

Diversity training adds meaning to gestures, language and other communication that were previously unfamiliar, thereby improving the accuracy of the message between the source and receiver. The human mind cannot comprehend something that is entirely outside of its previous experience or knowledge (Brown, 1973). His suggestion supports the importance of sharing cultural, racial, gender and other diverse specific experiences in a safe "training" environment in an effort to resolve managerial and organizational conflicts. Developing an understanding of communication symbols allows the mind to move from the known to the unknown (Brown, 1973). The ideal outcome of a diversity-training program is to enhance the communicative openness within an organization, thereby contributing to the resolution of organizational problems. Given what is now known about diversity training from a top-down approach, what next?

\section{SERIES OF MANAGERIAL RECOMMENDATIONS}

The first recommendation for a top manager or CEO is to impose an organization wide diversity-training program to overcome diversity barriers and improve managerial communication. Diversity trends show a continuous increase over the years. The definition of diversity has become more contemporary, involving different cultures and backgrounds. Differences in diversity can create communication barriers. Diversity amongst an organization can adversely affect interpersonal dynamics, including communication (Wanguri, 1996). The top manager or CEO should take a series of steps to be successful with the implementation of the diversity-training program.

Effective communication is a major step in the leadership of an organization that requires a linear exchange of information and transference of meaning between the CEO (source) and receiver (any subordinate manager). Downward communication (typically directive) also requires that keen attention be paid to upward communication (typically informative). This process must start at the head of an organization as it migrates to the bottom. Inevitable distortions along the way must be managed, or they will become noise. The message of diversity training can be rendered ineffective since meanings and content of communication become unclear as it goes down an organization (Phillips, 1985). Therefore, it is important for the top-level manager to support diversity initiatives with each communication transaction consistently in order to overcome barriers created by noise and misinterpretation of actions.

The second recommendation to a top manager is to be conscious of cultural differences. The need to know how to communicate with people of diverse backgrounds is omnipresent. Complexity and sensitivity around diversity means organizations need to be prepared for resistance, and create initiatives to deal with it (Anonymous, 2003). The top leader must establish diversity objectives and hold employees accountable for achieving these objectives with direct measures, frequently evaluated. Corporate executives share the primary responsibility of creating a nonthreatening culture that encourages open communication for managers so that they are better prepared to manage an increasingly diverse organization. Simply stated, the top executive sets the tone for the respective organization. An ability to manage diversity and to execute diversity initiatives will have a direct impact on subordinates' ability to not only manage diverse groups, but to achieve better communication results. 
Managerial communications can be improved by top managers who effectively lead the diversity initiative, by taking on a key role in this initiative. The role of leadership is important in managing diversity to improve managerial communication. Diversity management should be treated as a business initiative. The ability to manage diversity effectively is an important aspect of a top leader. Diversity management skills may not be instinctive to managers, which is another reason why diversity training is important. While there may be several strategic initiatives suitable to address the diversity management challenge, diversity-training programs have proven to be quite effective. Once senior management is behind the diversity initiative, the next step is to introduce training programs (Kaminsky, 2001). Organizations are rapidly changing to accommodate expanding markets therefore, creating a need for diversity training.

The source of diversity-training message is the top manager of the organization. The CEO is the source of that message. The effectiveness of diversity training is dependent on the receivers' perceptions of the source's credibility, sincerity, and knowledge; therefore, top leaders must understand the affects of communication barriers regarding diversity messages, and how to overcome them through properly imposed diversity training. If the leader does not demonstrate knowledge and understanding, the message to the receiver will be distorted, thus, hindering the communications process. Training programs must help managers develop leadership skills needed to promote constructive conflict and effective communication (Kochan, Bezrukova, Ely, Jackson, Joshi, Jehn, et.al, 2003). Diversity training programs should be imposed and implemented to overcome communication barriers; subsequently, how do managers implement an effective diversity-training program?

The third recommendation for a top manager is to integrate diversity training into the overall corporate level strategy, to promote diversity awareness and stimulate serious managerial communications at both the tactical and operational levels. Successful training should employ strategic initiatives and behavioral modeling techniques. Training programs should improve skills, awareness, and sensitivity to diversity issues. The entire organization should be focused on skill building and awareness training for positive diversity results.

The final recommendation for a top manager is to promote skill building training and insist that it be used to provide tools to promote effective interaction in a heterogeneous work environment. Awareness training enhances knowledge employees will have toward cultural issues (Grant, Kleiner, 1997). It promotes sensitivity and awareness to diverse cultures, which helps decrease negativity and miscommunication. If managers effectively employ skill building and diversity training awareness, the CEO's message will have a positive effect, thus minimizing noise in the CEO communication process. This can reduce negative feedback and improve communication. The effectiveness of this training contains a combination of strategies before, during, and after to calibrate measurable benefits.

There are many benefits to diversity training. It creates awareness of other cultures and different groups. It can be used to encourage cohesiveness and create a more productive work environment. It can help members within an organization to overcome misconceptions of different cultures and promote understanding of individual differences. Diversity management training teaches motivational skills and leadership theories to managers. These skills help to eliminate stereotypes that occur within an organization's culture. It can support valuing diversity and improving communication. It causes managers to focus on being part of the solution. Organizations that have integrated diversity training with long-term strategic plans are more likely to have success with diversity training (Rynes \& Rosen, 1994). Top management involvement and support are essential for long-term change as well as embedding training with a larger change effort (Arai, Wanca-Thibault, \& Schockley-Zalabak, 2001).

\section{CONCLUSION}

The CEO or top-level executives imposing the implementation of a diversity-training program could mean downward communications improve and diversity resistance be diminished. Barriers in communication caused by diversity and cultural differences can be overcome, as evidenced in the literature. Once these barriers are broken, diversity can be used as a competitive advantage for organizations - instead of an obstacle in the communications process. The implementation of quality programs will allow subordinate managers and employees to follow the top manager's lead and understand the benefits of diversity in the workplace (Kaminsky, 2001). The benefits of a CEO supported diversity training program can dramatically minimize the communication barriers regarding the current 
need for organizational diversity and enhance managerial communications, at all levels, which will benefit the entire organization. The CEO must be the source of the message from top to bottom.

\section{REFERENCES}

1. Arai, M., Wanca-Thibault, M., \& Schockley-Zalabak, P. (2001). Communication theory and training approaches for multiculturally diverse organizations: Have academics and the practitioners missed the connection? Public Personnel Management, 30, 411.

2. Barbian, J. (2003, February). Moving toward diversity. Training, 40(2), 44.

3. Brown. D. J. (1973). The Human Nature of Organizations. New York: AMACOM, 14.

4. $\quad$ Capowski, G. (1996, June). Managing diversity. Management Review, 13-19.

5. Daft, R.L., Bettenhausen, K.R., \& Tyler, B.B. (1993). Implications of top managers' communication choices for strategic decisions. Huber, G.P. and Glick, W. H. (Eds.), Organizational Change and Redesign: Ideas and Insights for Improving Performance. New York: Oxford University Press.

6. Drucker, P.F. (1974). Management: Tasks, Responsibilities, Practices. New York: Harper \& Row, Publishers.

7. Gardenswartz, L. \& Rowe, A. (2001, November). Strategic Planning: 10-Step plan to build a stronger diversity-training program. IOMA's Report on Managing Training and Development, 1(11), 3.

8. Gilbert, J., Stead B., \& Ivancevich, J. (1999, August). Diversity management: a new organizational paradigm. Journal of Business Ethics, 21(1), 15.

9. Grant, B., and Kleiner, B. (1997). Managing diversity in the workplace. Equal Opportunities International, 16(3), 26-33.

10. Gray, R and Robertson, L. (2005, July/August). Effective internal communication starts at the top. Communication World, 22(4).

11. Grossman, R. J. (2000, March). Race in the workforce. HR Magazine, 45(3).

12. Hudson Institute. (1987). Workplace 2000. Indianapolis, IN.

13. Kaminsky, A. (2001). Training and development needed for successful diversity plan. Canadian HR Reporter, 14(12), 7.

14. Katz, D. \& Kahn R. (1966). The social psychology of organizations. New York: John Wiley \& Sons, Inc.

15. Klein, Jeffrey S. (2004). Corporate cultures: why values matter. Folio: The Magazine for Magazine Management, 33(12), 1.

16. Kochan, T., Bezrukova K., Ely R., Jackson S., Joshi A., Jehn, K., et.al. (2003, Spring). The effects of diversity on business performance: report of the diversity research network. Human Resource Management, 42, 3-21.

17. Koonce, R. (2001). Redefining diversity. $T \& D$, 55(12), 11.

18. Lewis, P., Goodman S., and Fandt P. (2005). Management: Challenges in the $21^{\text {st }}$ Century. West Publishing Company.

19. Littlejohn, S. W. (1989). Theories of Human Communication, $3^{\text {rd }}$ ed. Belmont, CA: Wadsworth Publishing Company.

20. Making race and diversity-training work. (2004). Women in Management Review, 18 (1/2), 101.

21. Morand, D. (1995, October). Politeness as a universal variable in cross-cultural managerial communication. International Journal of Organizational Analysis, 3(4), 22.

22. Munter, M. (1993). Cross-Cultural Communication for Managers. Business Horizons, 36(3), 69.

23. Phillips, J.J. (1985). Improving Supervisors' Effectiveness. San Francisco: Jossey-Bass Publishers

24. Pollar, O. (1998, December). A diverse workforce requires balanced leadership. Workforce, 1 .

25. Reichenberg, N. (2001, May). Best practices in diversity management. United Nations Expert Group Meeting on Managing Diversity in the Civil Service.

26. Shockley-Zalabak, P. (1988). Fundamentals of Organizational Communication. New York: Longman.

27. Rynes, S. and Rosen, B. (1994, October). What makes diversity programs work? Hr Magazine, 39(10), 7.

28. Smeltzer, L., Leonard, D., Hynes, G. (2002). Managerial Communication: Strategies and Applications (2 ${ }^{\text {nd }}$ ed.). New York: McGraw-Hill.

29. Swanson, D. (2002). Diversity programs: attitude and realities in the contemporary corporate Environment. Corporate Communications, 7(4), 257. 
30. Turner, Robert M. (1992). Managing diversity in the accounting profession. Massachusetts CPA Review, 66(3), 3.

31. Von Bergen, C. W. (2002). Unintended negative effects of diversity management. Public Personnel Management, 31, (213).

32. Wanguri, D. (1996, October). Diversity, perceptions of equity, and communicative openness in the workplace. Journal of Business Communication, 33(4), 15. 